Bulletin d'Histoire Contemporaine de l'Espagne

$50 \mid 2016$

Les intellectuels en Espagne, de la dictature à la démocratie (1939-1986)

\title{
Entre Masoch y Narciso: un escaparate cultural (1960-1975)
}

Entre Masoch et Narcisse: une vitrine culturelle (1960-1975)

Between Masoch and Narcissus: a cultural shop window (showcase) (1960-1975)

José-Carlos Mainer

\section{OpenEdition}

\section{Journals}

Edición electrónica

URL: http://journals.openedition.org/bhce/495

DOI: $10.4000 /$ bhce.495

ISSN: 1968-3723

Editor

Presses Universitaires de Provence

Edición impresa

Fecha de publicación: 1 diciembre 2016

Paginación: 43-48

ISSN: 0987-4135

Referencia electrónica

José-Carlos Mainer, «Entre Masoch y Narciso: un escaparate cultural (1960-1975) », Bulletin d'Histoire Contemporaine de l'Espagne [En línea], 50 | 2016, Publicado el 09 octubre 2018, consultado el 29 septiembre 2020. URL : http://journals.openedition.org/bhce/495 ; DOI : https://doi.org/10.4000/bhce 495 

guerra fría. Estos regalaron al «Centinela de Occidente» una nueva legitimación (el Concordato de 1953 y los pactos secretos del mismo año con los Estados Unidos), a la vez que señalaron el final de la época de la autarquía y su doloroso reemplazo por una economía más abierta. Pero, sobre todo, el decenio registró la lenta salida del purgatorio de artistas e intelectuales que habían perdido la guerra y, a la vez, el ingreso en la juventud de una promoción a la que, años después, una de las más sensibles de sus componentes -Josefina Rodríguez Aldecoa- llamaría de los «niños de la guerra». La suma de ambas cosas fue lo que en alguna otra ocasión he llamado «la constitución de una literatura de postguerra».

Por supuesto, las circunstancias de su nacimiento y desarrollo distaron mucho del despertar crítico de la vida intelectual en Italia y Alemania, nada más acabar 1945, o de los cambios que el decenio anterior vio desarrollarse en la cultura francesa (a favor de la marea existencialista, aunque no sólo) y que los finales de los cincuenta presenciaron en el Reino Unido de los angry young men. El modelo español de lo que luego se llamará la «generación de los cincuenta» se desarrolló en un clima de insuficiencias estructurales, poblado de recelos, e incluso no pocos de sus miembros mantuvieron una ambigua relación inicial con el Régimen, con sus viejos resortes populistas y con su escalafonamiento cultural.

Pero lo esencial estuvo ahí, a veces en el centro de sus mismas contradicciones: una actitud de compunción, comprensión y solidaridad con todo lo que la contienda reciente había significado y, en consecuencia, la conquista -o el descubrimiento- del término «guerra civil» para denominar aquello que aconteció en la edad de sus padres y que, en modo alguno, podría calificarse como «Cruzada» ni «Guerra de Liberación». He citado a menudo unos versos del jovencísimo Carlos Sahagún en 1958, que son todo un emblema generacional, una proclamación de inocencia y una toma de posesión, a la par: «Le llamaron posguerra a este trozo de río, / a este bancal de muertos, a la ciudad aquella / doblada como un árbol viejo...» («Río», en Profecías del agua).

Por otro lado, la ya aludida presencia de vencidos y represaliados en la cultura empezaba a ser llamativa. No se aireaban los antecedentes de unos y otros y sólo los amigos sabían el lugar de donde procedían Antonio Buero Vallejo y José Hierro, Juan Antonio Gaya Nuño y Julián Marías, Leopoldo de Luis y Ramón de Garciasol, Dolores Medio e Ildefonso Manuel Gil, por citar unos pocos portadores de cierto indeleble carisma del pasado en llamas y de un aroma de libertad republicana. Ocupaban un lugar ya ineludible con sus versos, sus novelas o en sus estrenos, como lo representaban también las esbeltas (y sólo 
aparentemente asépticas) páginas de la revista Ínsula y las propuestas artísticas del grupo Altamira, como alguna de las actitudes que ya se esbozaban en Revista y en Destino, o el hecho de que cada vez se mencionara más admirativamente a Picasso y Miró. Volveremos inevitablemente sobre las consecuencias de esta relación con el pasado...

En tal sentido, los años sesenta fueron una consecuencia de aquel despertar a otra realidad y también síntomas visibles de la arribada de otro tempo: el nuevo decenio legitimó pronto las viejas palabras «huelga» y «obreros», a la vez que las más mendaces, como «desarrollo» y «democracia orgánica». Y también fue testigo de las consecuencias de otro reemplazo generacional, que sumó fuerzas al anterior. En parámetros europeos, la comparecencia de los babyboomers -los «niños de la posguerra», diríamos ahora- lo había modificado todo: los horizontes del consumo de bienes en una sociedad que había crecido bastante, las exigencias de explicaciones sobre el pasado cercano, los hábitos propios de una socialización distinta, el crecimiento de una protesta difusa pero ruidosa. No es que aquellos síntomas faltaran entre nosotros, debidamente amortiguados. Y lo cierto fue que, en torno a 1960, las fuerzas tradicionales -el Movimiento o la Iglesia católica-registraron con aprensión la presencia de una juventud malcriada, ignorante de los sacrificios que les permitían vivir como nunca se había hecho, y reclamar de sus mayores algo distinto.

A su respecto, la Iglesia y el Estado practicaron el aviso monitorio y una indulgencia limitada, y muy a menudo, la queja apocalíptica. El cine y la novela comerciales de la época abundaron en títulos que reflejaban la confrontación intergeneracional, en términos que van de la comprensión y los paños calientes al repudio indignado. Los estudiantes universitarios de Muerte de un ciclista (1955), de Juan Antonio Bardem, encarnaban el último refugio de la honestidad en un horizonte de vileza moral, como los personajes jóvenes de Encerrados con un solo juguete (1958), de Juan Marsé, podían atisbar el naufragio colectivo en que debían construir sus vidas. Pero narradores como Torcuato Luca de Tena (Edad prohibida, 1958) y el sacerdote José Luis Martín Vigil (La vida sale al encuentro, 1960) tenían todo más claro... Y en un singular cóctel de fascismo y crítica de costumbres como Juventud a la intemperie (1961), filme del prolífico Ignacio F. Iquino, con guión de Federico de Urrutia (el olvidado autor de los Poemas de la Falange eterna, de 1938), se mezclaba todo: las denuncias de la podredumbre de la burguesía, la mezcla de insensatez y generosidad en los jóvenes y la exaltación de un excombatiente que, a tiros y mamporros, resolvía todo (algo que, por otra parte, no dejaba de estar relacionado con las dos versiones del filme que se rodaron; en la que se vendió fuera de España, la strip-teaseuse francesa Rita Cadillac-actriz secundaria en los créditos que se exhibieron aquí- figuraba como protagonista principal...).

Un poco después y en este mismo ámbito, vino a producirse lo que, en términos algo enfáticos, he llamado alguna vez «la derrota cultural del régimen». Obedeció, por un lado, a la lenta emergencia de una clase media más moderna y, por otro, al significativo incremento de una minoría obrera más preparada y levantisca, pero también a una decisión del mismo conglomerado franquista gobernante: la campaña de propaganda sobre los «XXV Años de Paz» (1964) y la gestación de la Ley de Prensa (1966), ambas obras del equipo de Fraga Iribarne, tuvieron, a la vez, algo de concesión parcial sobre el significado del intangible «18 de julio» y de repliegue táctico que desplazó las trincheras un poco más allá de donde estaban. Y, muy pronto, en los aspectos culturales más creativos fue perceptible el simple abandono de las posiciones. En los años cincuenta, el franquismo había convivido -e incluso contemporizado-con los inicios de la abstracción pictórica, con la nueva arquitectura y con la música atonal, que subvertían el orden estético pero no los valores morales; en los años 
del rock, de la «nueva cultura» radical, del pop, del teatro político y del marxismo cultural, no tuvo más opciones que el eclipse de mala gana o la prohibición sin contemplaciones.

En procesos de esta naturaleza nunca hay fechas ni acontecimientos precisos sino síntomas. Lo fueron, por ejemplo, las dos actitudes que dirigieron sus pasos hacia el pasado cancelado y hacia el presente emergente: los abiertos diálogos con el exilio republicano de 1939 y con la emergente literatura latinoamericana. El primero impugnaba una ruptura cultural que siempre había sido incompleta para los mayores, pero que era efectiva para los más jóvenes; el segundo quebrantaba, en el fondo, la actitud de hegemonía y maternal tutela que la retórica oficial mantenía con respecto a la «Hispanidad». Los primeros atisbos de atención al mundo del exilio vienen de atrás, pero no mucho. En la segunda mitad de los años cincuenta, se logró ocultar la condición de exiliados de Juan Ramón Jiménez e incluso de Severo Ochoa, en ocasión de recibir ambos el Premio Nobel.

En los años sesenta, sin embargo, el regreso a las tablas de Alejandro Casona, la presencia asidua de Francisco Ayala, la apertura del Museu Picasso en 1963, las páginas de revistas como Ínsula o la publicación de la monografia Narrativa española fuera de España, de José Ramón Marra-López, dieron especificidad al hecho político del exilio, señalando implícitamente víctimas y culpables, y apuntando también el camino del reencuentro. Una colección de libros como «El Puente», de Editorial Hispano-Argentina (EDHASA) e inspirada por Guillermo de Torre, materializó desde 1963, pese a sus dificultades con la administración, un camino sin retorno que ya en el final del decenio y principio del siguiente trajo a figuras como Max Aub o Ramón J. Sender hasta un grado impensable de notoriedad pública.

Cuando, en 1962, Mario Vargas Llosa ganó el premio Biblioteca Breve con La ciudad y los perros, uno de los jurados que lo otorgaron por unanimidad, José María Valverde, declaraba a la prensa no haber leído mejor novela americana desde Don Segundo Sombra, de Güiraldes... que se había publicado, por cierto, en 1926. Reconozcamos que Valverde y muchos otros supieron enseguida que, en aquel largo ínterin, no sólo se habían escrito broncas novelas criollas o indigenistas sino que habian iniciado sus carreras literarias Julio Cortázar, Juan Rulfo y Carlos Fuentes, y que Miguel Ángel Asturias, Jorge Luis Borges y Alejo Carpentier ya habian tenido un capítulo editorial español anterior a 1936. Los más jóvenes descubrieron además que la lección evidente de las recientes letras americanas era la compatibilidad de escribir para la revolución y para pasárselo bien. Y muy pronto, los nuevos narradores españoles fueron legitimos herederos de Rayuela, Pedro Páramo y Cien años de soledad.

El diálogo con el exilio fue, por otro lado, un primer síntoma de reconocimiento del pasado cercano. Y, en tal sentido, coincidió con la recuperación sistemática de otros parajes de la historia española que, hasta entonces, eran casi patrimonio exclusivo de hispanistas laboriosos, habitualmente progresistas: aquellos que formaban lo que Jean-François Botrel ha llamado «hispanismo de sustitución». Los años sesenta vieron el rescate de universos ideológicos paladinamente declarados hostiles por el franquismo académico. Entre ellos estuvo la Ilustración dieciochesca (donde buena parte del mérito correspondió a la Cátedra Feijoo, de la Universidad de Oviedo) y del siglo XIX liberal, en cuya recuperación ya había dejado huella profunda el malogrado Jaume Vicens Vives. Del krausismo habló sin encono el libro de Vicente Cacho Viu sobre la Institución Libre de Enseñanza, publicado en 1963 bajo el escudo protector de Editorial Rialp y de un prólogo político de Florentino Pérez Embid, pero el trabajo del autor -miembro numerario del Opus Dei-no desmereció, 
ni mucho menos, del más explícito rescate de la filosofia social del krausismo que, poco después, hizo Elías Díaz, vinculado al socialismo académico de Tierno Galván.

La historia del movimiento obrero en el XIX dio sus primeros pasos en Barcelona bajo tutela de un criptoliberal, Carlos Seco Serrano, pero el primer planteamiento serio del problema se remontaba a una conferencia de José María Jover Zamora, Conciencia obrera y conciencia burguesa en la España del siglo XIX, que editó el Ateneo de Madrid en 1952. Apenas quince años después, los estudios de historia obrera eran el tema estrella de las tesis doctorales en preparación en casi todas las facultades españolas de Letras, aunque en la Universidad de Navarra - del Opus Dei-los títulos de los trabajos académicos hablaran de «relaciones laborales». De ese mismo periodo fueron los primeros estudios autóctonos sobre la Segunda República, la Guerra civil o, en el campo de la cultura, sobre la historia del vanguardismo español, ya no reducido a la cómoda abreviatura de la «generación del 27». De forma visible, se trataba de entroncar con el hilo rojo del pasado y enlazarlo a la madeja que se estaba tejiendo en el presente. No era un asunto de simples carencias bibliográficas remediadas, sino la conciencia clara de que, acercando las dos orillas, se deslegitimaba el designio franquista de refundar la historia de España.

En la primavera de 1975, la galería Multitud, de Madrid, acogió la exposición «Orígenes de la vanguardia» que fue meticulosamente organizada por el historiador del arte Valeriano Bozal con la intención de identificar, en lo que tocaba al periodo 1925-1936, el vanguardismo como lenguaje y la revolución como necesidad histórica. En el verano de 1976, el mismo Bozal se encargaba del pabellón español de la Bienal de Venecia que, por vez primera y tras su salida del lazareto franquista, tenía a España como país invitado. El cartel de la muestra exhibía el sello que Joan Miró había realizado en 1937 con el lema «Aidez l'Espagne!», que parecía cobrar nueva actualidad. Y las salas del recinto aunaban la historia contemporánea del arte disidente español -desde la primera abstracción hasta el reciente arte $p o p$ - con la reconstrucción del contenido artístico que albergó el Pabellón de la República Española, en la Exposición Universal de París, en 1937.

Muchas de estas cosas tiñeron de un cierto tono masoquista -compatible con la euforia y la decisión-el mundo cultural de comienzos de los años setenta. Esa sensación de desánimo y fracaso prematuros, que asaltaba a los héroes a la vista de los cambios inminentes, tuvo su expresión más llamativa (y, a veces, enfática) en el personaje de Álvaro Mendiola, de la trilogía de Juan Goytisolo que formaron las novelas Señas de identidad (1966), Reivindicación del Conde don Julián (1970) y Juan sin tierra (la única que vio la luz en España, en abril de 1975). La expresión plástica de la perplejidad morosa y del turbio vuelo de pájaros agoreros resultó indisociable del cine del remordimiento filmado por Carlos Saura. En 1965 acertó a dar en La caza una compleja y brutal alegoría de la guerra civil, que revive en una partida de antiguos combatientes vencedores, siempre bajo la luz quemada que inunda el escenario rural, fotografiado por Luis Cuadrado. En Pepermint frappé (1967), el actor José Luis López Vázquez asumió por vez primera las frustraciones y las miserias del franquismo ordinario y Geraldine Chaplin, el de la extranjera inocente de su condición de agente provocador; una estructura dialéctica que se reiteraría en Ana y los lobos (1972), parábola muy certera de la España inmemorial. Y, por supuesto, en las dos exploraciones de la impotencia para sobrevivir al pasado que fueron El jardín de las delicias (1970) y La prima Angélica (1975).

Acertó la estudiosa norteamericana Marsha Kinder al titular Blood Cinema: the Reconstruction of National Identity (1993) un estudio sobre la imagen de la familia y la 
violencia (sexual, sobre todo) en la historia del cine español, desde 1950 (Luis Buñuel) hasta Carlos Saura, Víctor Erice (El espíritu de la colmena, 1972), Manuel Gutiérrez Aragón (Habla, mudita, 1973) y José Luis Borau (Furtivos, 1975). Y quizá fueron los dos últimos, como guionistas y el último como director, los que lograron dar la más explícita lectura política a esta temática en la película Camada negra (1977), gestada en los años anteriores pero estrenada en los expectantes meses del primer gobierno Suárez, siempre amenazados por el fascismo montaraz y doméstico que aquellas vívidas escenas de Borau revelaban por vez primera.

No es fácil reconstruir lo que significaron las imágenes cinematográficas -ya fueran las pensadas por los realizadores, ya las percibidas por los espectadores en la oscuridad de una sala- para dos o tres generaciones de europeos que fueron jóvenes entre 1955 y 1980. La cinefilia fue una pasión internacional, que recibió nombre francés pero que estuvo presente como consolación propicia en la socialización de varias promociones de masoquistas de muchos lugares, desde Lisboa a Moscú. Y, por ese camino, sus partidarios llegaron a la construcción de un narcisismo íntimo, más doloroso que placentero, sin duda. Lo aprendieron de las películas del último Luchino Visconti y de su propensión a ver el esteticismo como una forma de la desesperación; encontraron un hermano en Antoine Doinel, el héroe autobiográfico de François Truffaut, capaz de sobrevivir a todo y de hallar muchos lechos hospitalarios con la ayuda de algún libro, de una desarmante sinceridad y de una egoísta inocencia; se proveyeron de algunas metáforas de la rebeldía en otras tantas citas filmicas de Jean-Luc Godard, desde À bout de souffle a Pierrot le fou, pasando por Bande à part. La cinefilia cursaba como enfermedad de signo formalista pero también encerraba una moral exigente. En tal sentido, el cahierismo proponía una nueva visión del cine clásico americano que se presentaba como una nostalgia de la épica perdida y como una apología de quienes, al final, serían perdedores: allí estaba lo que llamaban «el clasicismo» de John Ford, la moral de aventura de los dinámicos grupos de amigos retratados por Howard Hawks, o incluso los seres sufrientes que encadenaban sus desdichas en los brillantes y arrebatados melodramas de Douglas Sirk.

Puede que toda esta dieta filmica encaminara en derechura a la decepción y, por eso, el luego famoso «desencanto»-que sucedió a las angustias de 1975-tuvo síntomas muy precoces en gentes que ya habían sufrido los estragos de 1968. Hemos señalado más arriba que la certidumbre de la crisis estuvo presente - por lo que toca a escritores que estaban en la cuarentena de su edad- en las novelas de Juan Goytisolo, pero también fue el motivo del sarcasmo lúcido que exhibieron los relatos de Juan Marsé (desde Últimas tardes con Teresa hasta su abordaje de la posguerra civil en Si te dicen que cai) y Juan García Hortelano (El gran momento de Mary Tribune), así como de la complejidad de la visión autobiográfica que apareció en el ciclo «Antagonía», de Luis Goytisolo. No es casual que, de un modo u otro, muchos de estos escritores tuvieran alguna participación en la invención barcelonesa de la gauche divine, oportunamente bautizada por Joan de Sagarra, y donde hubo más de escenografia muy deliberada que de componente generacional: ser de izquierdas y, a la vez, divertido y exquisito fue un paradigma que no estaba al alcance, ni en los propósitos, de todo el mundo, pero vino a ser otra respuesta a una España políticamente estancada -como lo fue la de los primeros años setenta-y bastante impresentable.

La trayectoria de la poesía (y la persona) de Jaime Gil de Biedma ilustra, como ninguna otra, el recorrido que fue del compromiso político, que se expresaba en el «nosotros» enunciativo, hasta el refugio del egotismo como moral, que se modulaba en autobiografía, sin perder nunca el férreo control de la (mala) conciencia y de los versos. 
El libro Compañeros de viaje (1959) expresó la tensión voluntarista (y jubilosa, a ratos) de un proyecto vital colectivo (que fue patente en el poema «Amistad a lo largo»); tras la deslumbrante aparición de Moralidades (1966), los Poemas póstumos, de 1968, expresaron la mezcla de autocomplacencia y de hastío que el poeta había llegado a ganarse. Y, en un tono de abolengo estoico y con descaradas alusiones a la poesía clásica española, formulaba su anhelo de:

...un orden de vivir, es la sabiduría. / Y qué estremecimiento / purificado / me recorrería / mientras que atiendo al mundo / de otro modo mejor, menos intenso, / y medito a las horas tranquilas de la noche, / cuando el tiempo convida a los estudios nobles, / el severo discurso de las ideologías / -o la advertencia de las constelaciones / en la bóveda azul...

Algo de esto hubo también en la meditada decisión de Carlos Barral cuando publicó, en 1975, el primer volumen de sus recuerdos, Años de penitencia, donde el autor se aplicaba una sabia dosis de autoflagelación y otra de exhibicionismo que, sin duda, tenían muy en cuenta la aparición, años antes, del Diario de un artista seriamente enfermo -todavía incompleto-, de Jaime Gil.

¿Se había terminado el ciclo de la rebeldía? No lo daba a entender el mundo de la plástica coetánea que seguía siendo un activo campo de batalla. El pop art español tuvo una dimensión fundamentalmente política, como se advierte en la obra de Equipo Crónica, Equipo Realidad y el autoexiliado Eduardo Arroyo. Pero, de otro modo, ese compromiso también estuvo presente en el programa de la nueva abstracción, a veces cercana al expresionismo -como fue el caso de Antonio Saura- mientras que en otras trayectorias, como en los casos de Manolo Millares y Antoni Tàpies, el uso de materias y texturas ajenas a la pintura tradicional desembocaban en una suerte de proclamación de la realidad, a la que no era fácil permanecer indiferente en lo que tenía de ascética denuncia. Y otro tanto cabía decir de la potente volumetría de Eduardo Chillida, de las esculturas (y los libros) de Oteiza, o de las series temáticas de Pablo Serrano.

Porque paralelamente, y aunque el ambiente fuera de fatigosa expectativa, los síntomas de organización avanzaban a favor de la consolidación de nuevas clases medias y de significativos enclaves de proletariado industrial muy bien organizado, al margen de la cerrazón ambiente, pero no de la conciencia generalizada de deterioro de la situación política. La crisis crónica del mundo universitario, la perseverancia heroica de una prensa disconforme (que iba desde periódicos como Tele-Exprés, Madrid o Informaciones, hasta las más explícitas páginas de Cuadernos para el Diálogo y, sobre todo, Triunfo), las consecuencias sociológicas no previstas de la Ley General de Educación de 1970 (que fue un proyecto tecnocrático que acabó minando la estructura de un régimen arcaico), la existencia de librerías y galerías de arte que desafiaban a los ultras protegidos por la policía, la emergencia con visos de hegemonía de los sindicatos clandestinos en la vida laboral del país, todos eran sumandos efectivos en el pleito de desahucio que buena parte de la sociedad española había puesto al Régimen que la oprimía. 